\title{
Plain English in South Africa
}

(adapted from a press release issued by Plain English Campaign, P. O. Box 3, New Mills, Stockport, SK12 4QP, England: tel 01663744409, fax 01663-747038)

An international team of plain language experts visited South Africa recently to help Government officials get rid of gobbledygook and legalese from public information.

The trip came about after an invitation from Ministry of Justice representative Susan de Villiers. Plain language experts spent two weeks in South Africa talking with a wide variety of people including MPs, lawyers, academics, civil servants, consumer group representatives and insurance company executives.

Speaking at the Campaign's third international conference, held in Washington DC in 1994, Susan de Villiers explained that there was an urgent need to meet the expectations of the South African people. Amongst other things, the South African Government needed to:

- write a new constitution within the next 18 months

- provide a whole range of new legislation

- establish effective ministries of education, health and welfare

- demystify government activities

- get rid of the obscurities of government jargon

During the 1980s, the Campaign was brought in as a consultant to the Cabinet Office to help carry out a complete review of the British Government's communications. During this time over 171,000 forms were reviewed. Of those forms, 36,000 were scrapped and 58,000 were rewritten and redesigned. This work meant that many millions of pounds were saved in administration and printing costs. The Campaign now hopes to help set up a similar review for the South African Government.

Chrissie Maher, one of the founders of the modern plain language movement, explained, "If the plain language initiative in South Africa is as successful as our Campaign in the UK then the South African Government could save themselves a vast amount of money. That is money which is desperately needed to build houses and schools."

The international team included:

- Christopher Balmford from Phillips Fox Solicitors in Australia;

- Professor Shadrack Gutto, University of the Witwatersrand, South Africa;

- Professor Joseph Kimble from the Thomas M Cooley Law School in the USA;

- Philip Knight, a lawyer specialising in clear legal drafting from Canada; and

- George Maher and Janet Biggin from Plain English Campaign in the UK.

The Ministry of Justice also held a two-day seminar called "Plain language - the law and the right to information". This gave the international team the chance to meet the Government's legal experts who will be drafting the new legislation and the new constitution. During the seminar, the international team were able to take a close look at a draft of the new human rights legislation and advise on changes to improve its clarity. The team were able to show how legislation can be drafted in a clearer style without losing any of the precision of meaning that may be associated with the traditional style of legislative drafting.

Some of the suggestions made to improve the clarity of the new legislation included:

- using easily understood language when possible

- using must instead of shall

- avoiding redundant words and phases such as totally null and void

- setting the information out in a logical order

- "clustering" related information

- removing excessive cross-referencing

- setting out sequences of events in chronological order

- removing unintended ambiguities

- removing unnecessary detail

- avoiding unnecessary repetition

- using good typographical design

- testing major legislation on typical users

In South Africa it is absolutely vital that law texts are written as clearly and precisely as pos- 
sible. One of the reasons for this is that South Africa now has 11 official languages: English, Afrikaans, Ndebele, Pedi, Northern Sotho, Southern Sotho, Swati, Tsonga, Venda, Xhosa, and Zulu. The job of accurately translating law texts is difficult enough without having to interpret their meaning before translation.

The Minister of Justice, Mr Dullah Omar explained, "Simply translating what is obscurely written in English or Afrikaans into equally obscure Xhosa or Zulu is not the answer. We do not need 11 versions of gobbledygook. Any translator into an African language will tell you how she or he struggles with English that is written in a complicated and jargonistic way. So, whichever of our 11 languages we use, the principle remains the same. Communication should be clear, simple and understandable."

The Minister went on to explain that the issue of plain language does not only apply to law texts. He wants to see all the information that the Government produces for the public written in plain language. The Minister gave an example of how poorly-written maintenance grant forms are creating problems. He explained that according to latest available figures, only a shocking $0.3 \%$ of African children receive the grants they are entitled to. This figure seems unlikely to improve while Government forms remain unnecessarily complicated.

Professor Joe Kimble explained that one of the aims of the plain language movement was to revolutionise the language of the law. He went on to explain the misconceptions that some lawyers have about plain language. Here are some of the myths:

- plain language documents can't be precise

- plain language documents aren't "safe"

- you must only use short sentences and simple words

- plain language is patronising

- it is "baby language" or "street-talk"

- the plain language movement wishes to limit writers of poetry and literature

- plain language will devalue the image of the legal profession

Professor Kimble outlined the overwhelming evidence that judges, lawyers, and other peo- ple who have to deal with law texts prefer plain language versions to those written in a traditional style. He also explained how much time and money can be saved if law texts are written in plain language because readers will understand them better.

Christopher Balmford explained how the plain language movement in Australia has grown and how his law firm, Phillips Fox, has benefited from adopting plain language principles. He also explained some of the guidelines of drafting law texts in plain language and the work that had been done during his time with the Law Reform Commission of Victoria.

The Minister of Justice has asked the team to rewrite and redesign the Human Rights Commission Act. This will provide a useful model which will be distributed to legislative drafters together with a full report of the seminar.

Following on from the two-day seminar, Philip Knight was asked to suggest changes to the Correctional Services Amendment Bill and present the revision to the Select Committee on Correctional Services. He is a Canadian lawyer and consultant who specialises in clarifying law texts and business communications. He explained, "I only had a couple of days to work with the Bill, so I focused on the main problems as I saw them - passivity, excessive wordiness, legalese and over-use of cross-referencing. My goal was to reduce all four and have the law place the duty of compliance on the person actually able to perform the duty. By the end of our trip I believe we had achieved something really positive for the people of South Africa and the international plain language movement."

Plain English Campaign's Chrissie Maher adds, "We believe that it is vital that official information is provided in plain language. Without this, the people of South Africa have no chance of understanding what is going on around them and no chance of understanding their rights or responsibilities."

The international team now hopes to start a long-term training programme in South Africa to make sure that public information produced by the Government is clearly written and well designed. 